\title{
A SINGULARIDADE DA RECURSÃO NA LINGUAGEM HUMANA
}

\section{THE UNIQUENESS OF RECURSION IN HUMAN LANGUAGE}

\author{
Sidriana Scheffer Rettova"
}

Resumo: Este artigo trata do fenômeno recursivo das línguas naturais com base nos pressupostos teóricos da Gramática Gerativa de Noam Chomsky (1957). A noção de recursividade é uma questão polêmica e tem sido motivo de grande debate na literatura recente. Hauser, Chomsky e Fitch (2002) defendem a ideia de que a faculdade da linguagem seja dividida entre sentido amplo (FLB) e restrito (FLN), extraindo da Biolinguística traços que são compartilhados com os outros animais, e traços que são especificamente humanos. Assim a FLN é uma propriedade que envolve apenas a infinitude discreta com base na recursividade e é única ao ser humano. No entanto, Pinker e Jackendoff (2005) desafiam a hipótese da recursividade como componente exclusivo à linguagem humana. Os autores argumentam que há outros elementos que também podem ser únicos à faculdade humana da linguagem e que a recursividade parece desempenhar um papel em outros sistemas da cognição humana.

Palavras-chave: Recursividade, Faculdade da Linguagem em Sentido Amplo, Faculdade da linguagem em Sentido Restrito.

ABSTRACT: This paper discusses the recursive phenomenon of natural languages based on the theoretical assumptions of Generative Grammar by Noam Chomsky (1957). The concept of recursion is a controversial issue and it has been the subject of great debate in recent literature. Hauser, Chomsky and Fitch (2002) defend the idea that the language faculty is divided into broad sense (FLB) and narrow sense (FLN), extracting from Biolinguistics traits that are shared with other animals, and traits that are specifically human. So FLN is a property that only involves discrete infinity based on recursion and it is unique to humans. However, Pinker and Jackendoff (2005) challenge the hypothesis of recursion as a unique component of the human language. The authors argue that there are other elements that can also be unique of the human faculty of language, and that recursion seems to play a role in other systems of human cognition.

KEYwords: Recursion, Faculty of Language in the Broad Sense, Faculty of Language in the Narrow Sense.

\footnotetext{
"Mestrado em Linguística e Letras pela Pontifícia Universidade Católica do Rio Grande do Sul, Brasil (2014).

E-mail: sidri_rottava@yahoo.com.br
} 


\section{INTRODUÇÃO}

A noção de recursividade há muito tem desempenhado um papel importante no desenvolvimento do campo da Linguística, mais especificamente na abordagem Gerativa. Porém, o interesse pelo fenômeno recursivo das línguas naturais é bem mais antigo. Descartes procurou ressaltar a diferença entre o homem e o animal através da racionalidade e da variante linguística. Da mesma forma, dois séculos mais tarde, Wilhelm von Humbolt chamou a atenção à capacidade humana de fazer o uso infinito de meios finitos. Contudo, Descartes e Humbolt ainda não haviam falado precisamente sobre recursão, e infinitude poderia ser produzida por outros meios.

Foi a partir dos estudos linguísticos de Noam Chomsky (1957) que uma teoria formal linguística com princípios recursivos desenvolveu-se tendo um modelo matemático preciso de linguagem baseado na recursividade. Chomsky mostrou que a noção central da teoria das funções recursivas formais poderia ser adaptada à linguagem, partindo do pressuposto de que um processo recursivo é aquele que pode reaplicar-se indefinidamente, dando origem a uma estrutura hierárquica, visto que, até o momento, a linguística estruturalista, na sua vertente norteamericana, havia realizado uma descrição das relações estruturais em termos de constituintes imediatos.

Com o avanço da teoria, algumas regras foram sendo eliminadas e a recursividade passou a fazer parte da estrutura profunda das frases. Atualmente, com o Programa
Minimalista (CHOMSKY, 1986), houve um redirecionamento da teoria linguística em relação ao estudo da função dos itens lexicais às interfaces semânticas e fonológicas, e um único mecanismo é identificado para esta função, denominado Merge. Chomsky tem sido enfático ao afirmar que a recursividade subjaz ao mecanismo Merge e é esse processo que constrói recursivamente os objetos sintáticos a partir dos itens lexicais (CHOMSKY, 1995).

Ainda assim, o termo recursividade é problemático, visto que não há um consenso sobre o seu conceito, e as definições disponíveis na literatura, muitas vezes, são vagas e imprecisas em fornecer uma explicação. Certas definições salientam o encaixamento das estruturas recursivas, outras utilizam as regras de estrutura frasal como base, outras simplesmente equiparam a recursividade à repetição e à iteração.

Apesar de todas essas controvérsias e indefinições envolvendo o tema recursividade, háaproximadamente10anos, a pesquisa sobre o fenômeno recursivo das línguas naturais passou a delinear-se sob a perspectiva biolinguística e assim um novo viés de pesquisa desenvolveu-se desde o trabalho de Marc Hauser, Noam Chomsky e Tecumseh Fitch (HCF). Com a publicação de um artigo, Hauser, Chomsky e Fitch (2002) formulam uma nova hipótese envolvendo recursão. Os autores diferenciam a faculdade da linguagem entre Sentido Amplo (Faculty of Language in the Broad Sense - FLB) e Restrito (Faculty of Language in the Narrow Sense - FLN), extraindo da Biolinguística a distinção entre os traços humanos que podem ser relegados a 
capacidades cognitivas gerais que, de acordo com HCF, são compartilhadas com outros animais, e traços que são especificamente humanos. Assim, a FLB é constituída por um sistema sensório-motor, intencionalcomputacional e computacional interno, que é a faculdade da linguagem em sentido restrito (FLN), e a FLN apenas envolve a propriedade da infinitude discreta, com base na recursividade.

Contudo, essa hipótese tem sido vigorosamente desafiada por Pinker e Jackendoff (P\&J) (2005) que, apesar de concordarem com a distinção entre a faculdade da linguagem em sentido amplo e restrito, apresentam vários contrapontos aos argumentos de HCF. P\&J consideram que a hipótese da recursão como o único componente da linguagem em sentido restrito partiu dos conceitos do minimalismo e este ignora muitas propriedades fundamentais da linguagem, tal como a fonologia, o léxico, a morfologia e os dispositivos sintáticos, como pronomes, artigos, complementizadores, auxiliares, quantificadores, modo e aspecto, os quais desempenham um papel importante na sintaxe das línguas naturais e que, pelo menos, alguns desses outros aspectos também podem ser únicos à faculdade humana da linguagem. Além do mais, os autores sugerem que a recursividade parece desempenhar um papel em outros sistemas da cognição humana, como, por exemplo, na música ou na formulação de sequências de ações complexas.
A Faculdade da Linguagem em Sentido Amplo e Restrito

A noção de recursividade sempre teve um lugar de destaque na Teoria Gerativa na hora de fornecer uma explicação para algumas das características mais relevantes das línguas humanas, em particular, a infinitude discreta, ou seja, a propriedade que um conjunto de possíveis expressões linguísticas tem de ser infinita. Assim para Chomsky (2000) recursividade é uma qualidade peculiarmente humana que é sinônimo de infinitude discreta, e que, muitas vezes, é tomada como sinônimo de criatividade e produtividade linguística, além de ser governada por determinadas regras. Segundo o linguista (CHOMSKY, 2000), os enunciados que produzimos têm certa estrutura gramatical: eles estão em conformidade com regras de boa formação identificáveis e são regidos por propriedades extremamente formais iguais às que se aplicam no campo das Ciências Formais.

Chomsky, juntamente com Marc Hauser e Tecumseh Fitch (HCF) (2002) surpreendeu o meio acadêmico e científico com a hipótese de que a faculdade da linguagem pode ser examinada em aspectos que podem ser unicamente humanos, aspectos unicamente linguísticos e aspectos que abranjam ambos os domínios. Para tanto, os autores, distinguem a faculdade da linguagem em sentido amplo (FLB) e sentido restrito (FLN). A FLB é composta por um sistema sensório-motor, que envolve a fonética e fonologia, um sistema intencional-computacional, que abarca a semântica e pragmática, e um sistema 
computacional interno, que apenas envolve a propriedade de infinitude discreta, e que, no mínimo, inclui a capacidade de recursão.

Esse sistema computacional interno (sintaxe restrita) compõe a FLN, que é independente dos outros sistemas com os quais ele interage e faz interface. Assim, a FLN captura um conjunto finito de elementos e produz um conjunto potencialmente infinito de expressões discretas, sendo que cada uma delas passa pelos sistemas sensório-motor e conceitual-intencional que processa e elabora as informações e as coloca em uso na linguagem. Então, cada expressão constitui um pareamento entre som e significado. (HAUSER, CHOMSKY e FITCH, 2002, p. 1571).

A razão em distinguir a FLB da FLN, segundo os autores, se deve pelo fato de que a FLB contém todas as capacidades que suportam a linguagem, independentemente se elas são específicas à linguagem e unicamente humanas. HCF argumentam que tal distinção é feita pela pertinência em dividir o estudo da faculdade da linguagem em blocos, facilitando, assim, discussões interdisciplinares sobre a sua evolução.

A questão crucial relativa à hipótese de HCF baseia-se no fato de que, além da combinação dos mecanismos da FLB, algo sobre a faculdade da linguagem deve ser único com o objetivo de explicar a diferença entre os humanos e os outros animais (HAUSER, CHOMSKY e FITCH, 2005, p. 182), e o elemento que se mostra exclusivo e específico à linguagem a aos humanos é a FLN. Porém, os autores argumentam que muita pesquisa precisa ainda ser conduzida, inclusive em domínios cognitivos não linguísticos, como na matemática, navegação, música, entre outros, para obter dados comparativos e poder verificar se há outros componentes, além da recursividade, que compõem a FLN. Além disso, não descartam a possibilidade de que talvez todos os elementos da FLB, que inclui a FLN, sejam compartilhados com os outros animais e que apenas a combinação entre eles seja única à espécie humana.

Em geral, os autores formulam três hipóteses sobre a evolução da faculdade da linguagem:

1. A FLB é homóloga ${ }^{1}$ à comunicação animal;

2. A FLB é unicamente uma adaptação para a linguagem;

3. Apenas a FLN é uma propriedade unicamente humana.

A hipótese (1) sustenta que a FLB, incluindo a FLN, exista nos seres humanos e animais e seja constituída dos mesmos componentes que subjazem à comunicação em todas as espécies. Porém, no mundo animal ela pode se manifestar numa forma menos desenvolvida ou modificada.

\footnotetext{
${ }^{1}$ Achamos pertinente traçar a distinção que a Biologia apresenta entre o termo análogo e homólogo. De acordo com Wróbel (2012), traços análogos são aqueles que compartilham funções similares, porém cresceram em ramos diferentes na árvore evolucionária e não são o mesmo órgão. Um exemplo são as asas dos pássaros e das abelhas. Ambas são utilizadas para voar, mas no percurso evolucionário elas surgiram independentemente e não têm mais nada em comum, além de sua utilidade para voar. Por sua vez, traços homólogos, podem ou não ter uma função em comum. Considerando que eles têm um ancestral em comum, possuem uma estrutura que permite que ambos sejam vistos como um mesmo órgão. Então, a asa de um morcego, a perna dianteira de um cavalo e a mão humana tem funções bem diferentes, no entanto, todos são modificações de um membro de um ancestral mamífero.
} 
Em relação à hipótese (2), a FLB pode ser fruto de uma adaptação extremamente complexa para a linguagem, da mesma forma que um olho, cujo componente principal constitui um traço individual que foi resultado da seleção na história da evolução humana. Essa hipótese procura se sustentar partindo do princípio de que a FLB é tão complexa e tão perfeita para a comunicação que a única explicação possível para tamanha perfeição seja a seleção natural, que é capaz de gerar mecanismos biológicos para tamanhas complexidades funcionais. Embora mecanismos semelhantes possam existir em outras espécies, a versão humana pode ter sido modificada, talvez pela exaptação, a partir de outros contextos, tais como a inteligência social ou a fabricação de ferramentas.

Por fim, a hipótese (3) sugere que a FLB se baseia em mecanismos compartilhados com não humanos, conforme a primeira hipótese. Contudo, a FLN evoluiu recentemente e é única à espécie humana. Assim, uma grande parte da complexidade da linguagem deriva dos componentes periféricos da FLB, mas o mecanismo computacional recursivo subjacente à FLN parece ser limitado e restrito, contrariando a hipótese da adaptação, visto que a faculdade da linguagem, como um todo, apoia-se em algumas capacidades exclusivas aos seres humanos.

De acordo com os autores, as três hipóteses são possíveis de alguma forma, mas consideram algumas distinções essenciais entre elas. Por exemplo, as hipóteses (1) e (2) podem ter uma correspondência direta entre alguma modificação de algum traço envolvendo a FLB que possa ter ocorrido em humanos e em outras espécies. Embora muitos aspectos da FLB tenham surgido dessa maneira, a questão é se uma série de mudanças graduais poderia resultar na nossa capacidade de gerar sentenças ilimitadamente. Para HCF, mesmo que tais modificações tenham ocorrido durante nosso percurso evolutivo, parece inadequado que tenha resultado em uma capacidade tão peculiar à nossa espécie: a infinitude discreta. Assim, a hipótese (3) seria a opção mais plausível para, enfim, caracterizar o problema da evolução da linguagem.

Outra questão relevante e que separa a hipótese (2) da hipótese (3) é se a FLN, sendo única ao ser humano, constitui uma adaptação. Segundo os autores, não há motivo para crer que a FLN possa ser dissecada em vários traços, porém interligados, sendo que cada um deles pode ter evoluído de forma independente ou cada traço pode ter sido moldado pela seleção natural, visto a tênue conexão para a eficácia comunicativa. Para HCF, antes de ser uma adaptação, alguns aspectos específicos da faculdade da linguagem são spandrels.

O que os autores deixam evidente na defesa de sua hipótese é que a FLN mostrou ser uma solução perfeita para compor uma interface entre o sistema sensório-motor e o conceitual-intencional, permitindo, assim, que possamos nos comunicar através de uma variedade infinita de pensamentos. A FLN representa, então, uma computação adaptativa para a linguagem, mas pode ter evoluído por outros motivos. 
Talvez os maiores opositores à hipótese de HCF sobre os aspectos da linguagem que são unicamente humanos e unicamente linguísticos, que é a recursão sintática contida da FLN, sejam Steven Pinker e Ray Jackendoff (P\&J) (2005). Embora os autores concordem que há a necessidade de se fazer uma distinção entre a faculdade da linguagem em sentido amplo e sentido restrito (FLB e FLN) para uma melhor compreensão de como a linguagem evoluiu, P\&J não aceitam a hipótese de que a recursão seja o único aspecto exclusivo à linguagem, que possa ter evoluído para outras funções além dela e por isso não seja resultado de um processo adaptativo na evolução.

P\&J argumentam que há muitos outros aspectos da gramática que não são recursivos, mas que se mostram essenciais à linguagem, como a fonologia, a morfologia, caso e concordância, e muitas propriedades das palavras.

Com relação à fonologia, por exemplo, além do ser humano possuir um trato vocal na forma exata e possuir a habilidade de controlá-lo de maneira adequada para a produção dos sons, o conjunto de estruturas fonológicas de uma língua formam uma infinitude discreta, uma propriedade tal qual a propriedade sintática, ou seja, da mesma forma que uma língua possui um número ilimitado de estruturas sintáticas a partir de um número finito de elementos, também há um número ilimitado de estruturas fonológicas a partir de segmentos fonéti$\cos _{\text {finitos }}^{2}$. O princípio da combinação e a

\footnotetext{
${ }^{2}$ HCF não concordam que a fonologia seja essencial à linguagem, visto que ela pode ocorrer de outras formas, como por exemplo, a linguagem de sinais.
}

natureza dos processos de ajuste que a fonologia apresenta parecem ser específicos à linguagem. Além do mais, as estruturas fonológicas são um nível de representação crucial usado tanto na percepção quanto na produção dos sons.

Apesar de algumas propriedades combinatórias da fonologia também existirem em algumas espécies, tais como pássaros ou em alguns cetáceos, elas não aparecem em nenhum primata além dos humanos. As propriedades rítmicas da linguagem e da música podem ser unicamente humanas, visto que nenhum outro primata conseguiu, até o momento, e apesar de extensivo treinamento, produzir algum som rítmico, habilidade que aflora espontaneamente em qualquer criança. Então, ao que parece, as principais características da fonologia são especificas a linguagem, unicamente humanas e parecem ter evoluído de forma adaptativa como parte da faculdade da linguagem. Para P\&J, é inegável que a fonologia constitui um nível distinto de organização das línguas humanas.

Outro aspecto que P\&J consideram essencial à linguagem são as palavras ${ }^{3}$. Em primeiro lugar há muitas delas, o léxico de uma pessoa pode chegar a 50.000 palavras, muito mais do que qualquer animal treinado pode chegar. Também é surpreendente a variedade e a precisão dos conceitos - tanto abstratos como concretos -, que as palavras expressam e, o mais importante, todas as palavras têm que ser aprendidas.

\footnotetext{
${ }^{3} \mathrm{HCF}$ (2002) também reconhecem que as palavras possuem várias propriedades que parecem ser unicamente humanas.
} 
Além disso, as palavras não são apenas nomes para as coisas, elas também são marcadores para as categorias sintáticas, como verbo, preposição, etc., para argumentos codificados, como agente, tema, etc., e para restrições de seleção nas propriedades sintáticas de seus complementos, como, por exemplo, um núcleo regido por preposição, verbo finito, etc. Essas informações, que são partes idiossincráticas a cada palavra e devem ser estocadas no léxico, governam a forma que as palavras entram no componente recursivo da gramática (morfologia e sintaxe).

Assim, a partir dessas evidências, P\&J consideram difícil a ideia de que as palavras estejam fora da FLN, visto que a capacidade de representá-las e aprendê-las são parte de um sistema de conhecimento geral que evoluiu independentemente da linguagem.

No que concerne à estrutura sintática, na visão de $P \& J$ as funções sintáticas no sistema linguístico ajudam a determinar como o significado das palavras é combinado para formar o sentido das frases e sentenças. De acordo com os autores, a sintaxe emprega no mínimo quatro dispositivos combinatórios. O primeiro deles reúne as palavras hierarquicamente em frases sintáticas que correspondem aos constituintes e é o que HCF denominam de componente recursivo. O segundo dispositivo ordena palavras e frases em uma frase, como, por exemplo, especificando que um verbo de uma sentença apareça em uma determinada posição. ${ }^{4} \mathrm{O}$

\footnotetext{
${ }^{4}$ Embora a língua inglesa apresente uma marcação rígida na ordem das palavras, a grande maioria das línguas não possui uma rigidez em relação a isso.
}

terceiro dispositivo sintático é a concordância, ou seja, verbos ou adjetivos são flexionados em gênero, número e pessoa ou outras características classificatórias relativas aos substantivos. Por fim, o quarto dispositivo é a marcação de caso. Sintagmas nominais são marcados com flexões nominativas, acusativas, etc., que dependem do papel gramatical da frase em relação ao verbo, à preposição ou a outro substantivo.

De acordo com P\&J, diferentes línguas apoiam-se em diferentes mecanismos para expressar quem fez o quê para quem e outras relações semânticas. A língua inglesa, por exemplo, apoia-se na ordem das palavras e constituintes. Porém, várias línguas, como o russo e o latim clássico, não apresentam um rigor de ordem, mas possuem um sistema rico de caso e concordância. Além disso, as línguas apresentam inúmeros outros dispositivos para auxiliar na transmissão de informação, como pronomes, artigos quantificadores, marcadores de tempo e aspecto, complementizadores, auxiliares e a propriedade da dependência de longa distância que pode relacionar um pronome interrogativo, por exemplo, a um verbo distante na sentença.

Para P\&J, todos esses aspectos parecem ser específicos à linguagem, visto que há um maquinário especializado capaz de regular as relações entre som e significado. Caso contrário, para quais outras habilidades humanas eles poderiam servir? E, com exceção da estrutura frasal e dependência de longa distância, nenhum outro aspecto envolve recursão. Além disso, há uma recente descoberta de uma evidencia genética que, 
de acordo com P\&J, enfraquece a hipótese de HCF sobre a singularidade da recursão: o gene FOXP2, cuja versão normal é universal na população humana, mas apresenta, em alguns indivíduos, uma rara modificação que acarreta em um déficit na articulação, produção, compreensão e julgamento linguístico. Essa descoberta refuta a hipótese de que a única mudança evolucionária para a linguagem, na linhagem humana, foi a alteração na recursão sintática. Ao invés disso, ela sustenta a noção de que a linguagem evoluiu pouco a pouco sob a influência da seleção natural, através de genes seletivos capazes de aprimorar múltiplos componentes.

No entanto, a influência do gene FOXP2 sobre o controle da linguagem ainda não está de todo desvendada. Conforme Di Sciullo et al. (2009), uma análise mais minuciosa na estrutura do gene sugere que a proteína transcrita nele pode não implicar diretamente no aspecto computacional central da linguagem, visto que indivíduos com déficit linguístico possuem também um déficit no controle motor que não se limita apenas à linguagem. Analisando seu papel em outras espécies, reforça-se a suspeita de que ele implique no sistema sensóriomotor responsável pelo controle motor e planejamento de movimentos sequenciais. Então, na linguagem, o gene FOXP2 pode implicar em parte do maquinário que compõe esse sistema que é responsável pela fluência verbal.

De qualquer forma, P\&J acreditam que, na medida em que mais genes responsáveis pelo discurso e pela linguagem sejam identificados, sequenciados e comparados entre as espécies, testes adicionais contrastando a hipótese da linguagem como adaptação com a hipótese da singularidade da recursão estarão disponíveis.

\section{CoNCLUSÃo}

Por ora, o debate Hauser, Chomsky e Fitch versus Pinker e Jackendoff sobre a centralidade da recursão na faculdade da linguagem encontra divergências em virtude das diferenças metodológicas sobre o que cada um deles entende por faculdade da linguagem. A ciência, principalmente de Chomsky, sempre teve um caráter formal e cognitivo ao mesmo tempo. Por isso, para Chomsky, a linguagem é forma e não conteúdo, de caráter interno e enraizado no cérebro. Para o autor, mesmo que as pessoas não falassem, ainda assim a linguagem existiria como propriedade. Assim, outros aspectos da linguagem, como a semântica e a fonologia, ficam relegados à parte externa (a FLB), porque o significado ou o som envolvem propriedades que não são da mesma natureza. O que permite que som e sentido se transformem em linguagem é a sintaxe, que para Chomsky é o componente essencial à linguagem.

Por outro lado, para Pinker e Jackendoff, a linguagem é uma propriedade interna e externa ao mesmo tempo, que forma um conjunto de atributos de várias naturezas e que evolui como qualquer outro ser vivo. Ela surgiu como uma adaptação para satisfazer a necessidade do ser humano de comunicar que fez o quê, para quem, quando e onde. Então, o essencial da linguagem 
é o seu potencial como um todo. Para os autores, não há como aceitar a divisão entre sintaxe, semântica e fonologia, porque a faculdade da linguagem é construída a partir dos três elementos combinados, dada a sua complexidade.

Apesar de todas as divergências entre Chomsky, Pinker e seus associados, é notório que todos praticam Linguística como Ciência Cognitiva. Conforme afirma Costa $(2013)^{5}$, os autores representam uma perspectiva que abalou as bases sócio-comunicativas. Seus fundamentos representam o ataque mais radical às Ciências Sociais enquanto Ciência da Linguagem.

\section{REFERÊNCIAS}

CHOMSKY, N. Syntatic Structures. Mouton: The Hague, 1957.

. Knowledge of Language. New York, New York: Praeger Press, 1986.

. The Minimalist Program. MIT Press:

Cambridge, 1995.

New Horizons in the Studies of Language and Mind. Cambridge: Cambridge University of Press, 2000.

DI SCIULLO, A. M. et al. The Biological Nature of Human Language. Biolinguistic, 2009. p. 1 $-33$.

HAUSER, M. D.; CHOMSKY, N.; FITCH, W.T. The Faculty of Language: What Is It, Who Has It, and How Did It Evolve? Science Compass, v. 298. p. 1569-1579, nov. 2002.

PINKER, S.; JACKENDOFF, R. The Faculty of language: what's special about it. Cognition, v. 95, p. 201-236, mar. 2005.

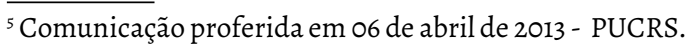

WRÓBEL, S. Rethinking language faculty. Has language evolved for other than language related reasons. Theoria et Historia Scientiarum.vol. IX, ed. Nicolaus Copernicus University, p. 202-215, 2012.

Recebido para publicação em 29 de mar. 2014 Aceito para publicação em 19 de maio de 2014 